Article

\title{
Experimental, Monte Carlo and Molecular Dynamic Study on Corrosion Inhibition of Mild Steel by Pyridine Derivatives in Aqueous Perchloric Acid
}

\author{
Avni Berisha ${ }^{1,2}$ (D) \\ 1 Department of Chemistry, Faculty of Natural and Mathematics Science, University of Prishtina, \\ 10000 Prishtina, Kosovo; avni.berisha@uni-pr.edu \\ 2 Materials Science-Nanochemistry Research Group, NanoAlb-Unit of Albanian Nanoscience and \\ Nanotechnology, 1000 Tirana, Albania
}

Received: 10 April 2020; Accepted: 21 May 2020; Published: 1 June 2020

\begin{abstract}
The corrosion of mild steel in aqueous perchloric acid solution was studied in the presence and absence of four different pyridine derivatives. Electrochemical measurements point out that these molecules inhibit the corrosion of mild steel by acting as mixed inhibitors. The adsorbed molecules act as a barrier that prevents the oxidation of the metal and the hydrogen evolution reaction at the mild steel surface. Molecular insights vis-à-vis the corrosion process were acquired by the use of Density Functional Theory (DFT), Molecular Dynamics, and Monte Carlo calculations. Monte Carlo and Molecular Dynamic simulation were used to understand at the molecular level the adsorption ability of the studied molecules onto $\mathrm{Fe}(110)$ surface. The experimental results and theoretical calculations provided important support for the understanding of the corrosion inhibition mechanism expressed by the pyridine molecules.
\end{abstract}

Keywords: corrosion inhibition; DFT; Monte Carlo; pyridine; molecular dynamic; adsorption energy

\section{Introduction}

Undoubtedly, steel is the most widely used material in construction and elsewhere. Although this material has optimal mechanic characteristics, like many other industrial metals it is prone to corrosion. In general, the use of strong acids in the industry is commonly found in different applications, such as in surface cleaning of metals, descaling, oil well acidizing, etc.

The protection of mild steel can be accomplished either by using classic corrosion inhibitors, spontaneous chemical surface modification methods such as SAM's (Self-Assembled Monolayers) formed from silanes [1,2], phosphonic acids [3], or electrochemical reduction of aryldiazonium salts $[4,5]$.

In order to prevent or decrease the corrosion of mild steel (MS), the most widely applied method is likely the use of a corrosion inhibitor-molecules, that in relatively low concentrations, decrease the corrosion of the metals. Many of the inhibitors are molecules that contain heteroatoms and other specific groups that are susceptible to the surface adsorption onto the metal [6-12]. The expressed inhibition efficiency of a particular inhibitor is dependent on many parameters, such as the composition of the corrosion media, $\mathrm{pH}$ value, temperature, contact time, chemical nature of the inhibitor, surface type, etc. [7-19]. To better understand the corrosion process apart from the use of experimental measurements, theoretical calculations were shown to be of great importance as they give molecular-level information for a better understanding of this process [6-11,19-26].

In the past two decades, there has been a growth in the number of studies that use theoretical methods based on quantum and molecular mechanics to gain molecular insights into the inhibitor 
interaction at the metal surface. These methods are able to pinpoint not only the adsorption mechanism of the inhibitor onto a metal surface (through the analysis of the electron exchange among both entities) $[18,27]$, but also how the corrosion species penetrates through the inhibitor films formed onto the metal $[12,28]$.

Pyridine, pyridine derivatives, and pyridine functionalized nanomaterials have shown their potential in their use as a potential means for reducing the corrosion of metals [18,29,30]. El-Maksoud et al. investigated the pyridine compounds [(2Z)-3-imino-4-methyl-2-(pyridin-3-ylhydrazono)pentanenitrile; 4-(3,4-dichlorophenyl)-2,6-dimethyl-1,2-dihydropyridine-3,5-dicarbonitrile] at the concentration of $1 \times 10^{-4} \mathrm{M}$ and achieved an inhibition efficiency of $\approx 70 \%$ [30]. The inhibition efficiency up $98.3 \%$ for Pyridine-2-thiol and 2-Pyridyl disulfide on the corrosion inhibition of MS using electrochemical measurements were reported by Kosari et al. [31]. Pyridoxol hydrochloride at a concentration of $1.0 \times 10^{-2} \mathrm{M}$ exhibited an inhibition efficiency of $\approx 72 \%$ [32].

In this study, the pyridine and three aminopyridine derivatives were studied at the molecular level using theoretical calculations based on both quantum and molecular mechanics to better understand the corrosion inhibition process.

\section{Materials and Methods}

The MS electrode (chemical composition: Fe99.5494\%, C 0.1252\%, P 0.0316\%, Mn $0.1831 \%$, Si $0.0561 \%$, Cr $0.0124 \%$, S $0.0282 \%$, Mo $0.0125 \%$, and Ni $0.0015 \%$ ) was prepared by inserting a MS wire $(\mathrm{d}=0.02 \mathrm{~cm}, 1=1 \mathrm{~cm})$ into a Teflon ${ }^{\circledR}$ tube and filling with an epoxy resin [6]. Before its use, the electrode was polished on $\mathrm{SiC}$ rough paper, then on a cloth (DP-Nap) wetted with an $\mathrm{Al}_{2} \mathrm{O}_{3}(0.3 \mu \mathrm{m}$ particle size) suspension. After this procedure, the electrode was rinsed with a copious amount of water and sonicated in water.

\subsection{Electrochemical Measurements}

A PalmSens3 potentiostat was used along with a three-electrode glass cell (with a total volume of $\left.25 \mathrm{~cm}^{3}\right)$ at $298 \mathrm{~K}$. A graphite $\operatorname{rod}(\mathrm{d}=0.03 \mathrm{~cm}, 1=4 \mathrm{~cm})$ served as an auxiliary electrode, and the saturated calomel electrode (SCE) as a reference electrode. Tafel curves were obtained by scanning the electrode potential vs. $E_{O C P}$ using a $1 \mathrm{mVs}^{-1}$ scan rate. The measurements were performed in atmospheric conditions.

\subsection{DFT Calculations}

DFT calculations were completed using the Dmol3 code. For geometry optimization, the double numerical plus polarization basis set (DNP) [33] was used in combination with the Perdew-Burke-Ernzerhof (PBE) functional within the Generalized Gradient Approximation (GGA) [34,35]. The dispersion energy in the DFT calculations was included by the Tkatchenko and Scheffler method [36]. The solvent $\left(\mathrm{H}_{2} \mathrm{O}\right)$ was incorporated via the COnductor-like Screening MOdel (COSMO) [37,38].

\subsection{Monte Carlo and Molecular Dynamic Simulation Details}

For Monte Carlo (MC) and Molecular Dynamic (MD) simulation, the interaction of the iron surface and inhibitor molecules (pyridine and aminopyridine derivatives) in the simulated corrosion media was performed via the Fe(110) model (with periodic boundary condition) with the size of $22.341 \AA \times 22.341 \AA \times 10.270 \AA$ with the inclusion of a $35 \AA$ vacuum layer at $C$ axis inclosing 400 water molecules/ 1 inhibitor molecule/ 15 hydronium +15 perchlorate ions. The temperature cycling in MC calculations was varied successively from $10^{5}$ to $10^{2} \mathrm{~K}$ during the 10 applied cycles (of $1500 \mathrm{steps}$ ), after which the lowest possible energy configurations were obtained at decreased temperatures. Before the MD, the simulation system was optimized until the energy met the $10^{-4} \mathrm{kcal} / \mathrm{mol}$ value. MD was conducted using a Constant volume/constant temperature (NVT) at $298 \mathrm{~K}$, with a $1 \mathrm{fs}$ time step and a simulation time of 500 ps $[8,10,16-20]$. The Berendsen thermostat [10] was used for temperature 
control. A COMPASSII force field [39], one of the most used forcefields in corrosion studies, was used for the simulations $[8,14,16-18,20]$. The Radial Distribution Function (RDF) analysis included the whole trajectory $[16,17,19]$.

As the experimental determination of thin inhibitor film formation at the interface of corroding metals is rather difficult [27], the film density of the inhibitors was determined using PBC (Periodic Boundary Conditions) by applying MD steps, as presented in Figure 1 (from STEP III).

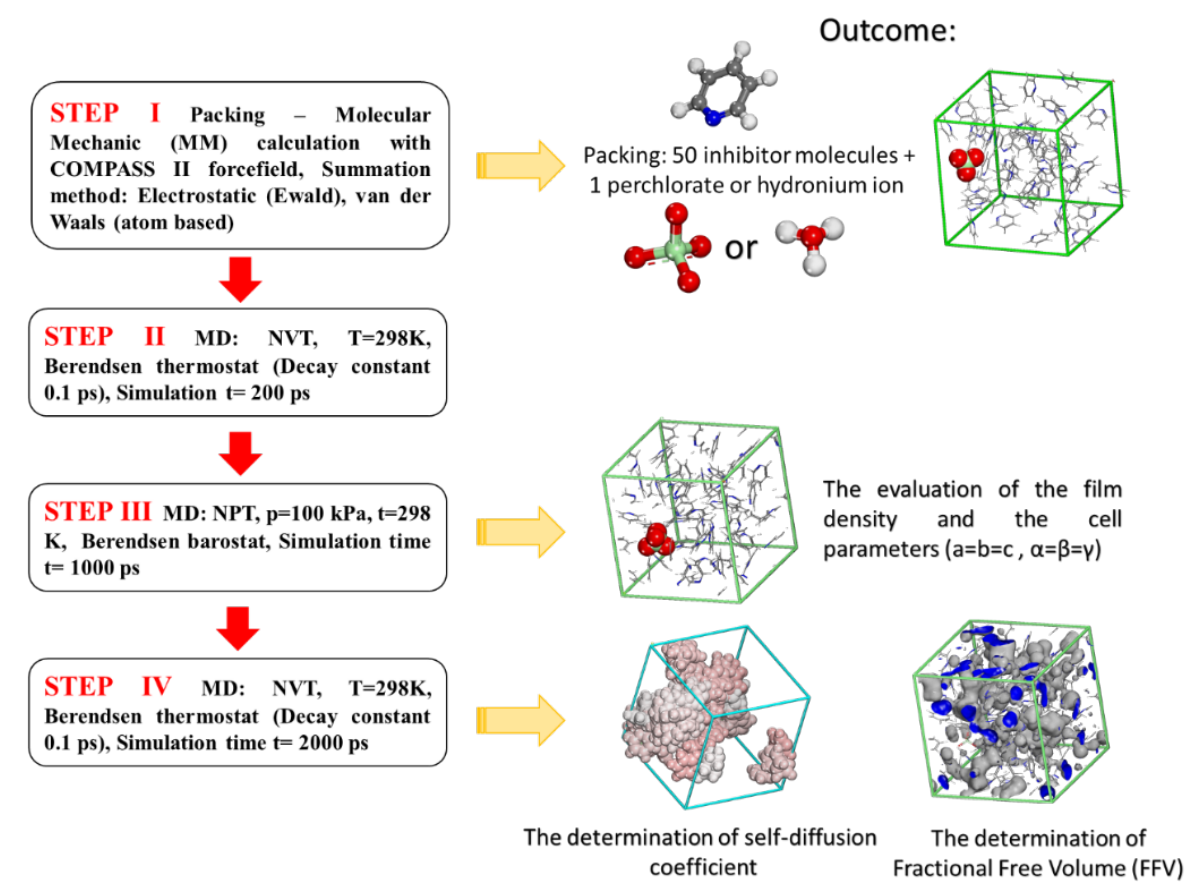

Figure 1. Steps used for the calculation of inhibitor film density, fractional free volume (FFV), and self-diffusion coefficients for the studied pyridine inhibitors.

\section{Results}

\subsection{Electrochemical Measurements}

The Tafel graph of the MS electrode in $0.1 \mathrm{M} \mathrm{HClO}_{4}$ are shown in Figure 2, in the absence and presence of pyridine inhibitors at $1 \times 10^{-3} \mathrm{M}$ concentration at $298 \mathrm{~K}$. The inhibition efficiency (IE (\%)) was calculated as follows $[6,18]$ :

$$
\mathrm{IE} \%=\frac{I_{\operatorname{corr}(0)}-I_{\operatorname{corr}(i n h)}}{I_{\operatorname{corr}(0)}} \times 100,
$$

where $\mathrm{I}_{\text {corr }(0)}$ is the corrosion current in the absence of the inhibitor, and $\mathrm{I}_{\text {corr(inh) }}$ is the corrosion current in the presence of corrosion inhibitor.

It is visible from the Tafel plots that the adsorption of the pyridine molecules, molecules on top of the MS surface, decreases the corrosion current in this aggressive media. Depending on the used inhibitor (Table 1), the corrosion inhibition efficiency ranges from $27.56 \%$ (pyridine) up to $68.38 \%$ (2-amino-3-benzyloxypyridine). These inhibitors act as mixed corrosion inhibitor types. Their inhibition efficiencies are interrelated to the presence of different substituents on the pyridine ring that affects their electron distribution and hence their adsorption ability onto the MS surface. 


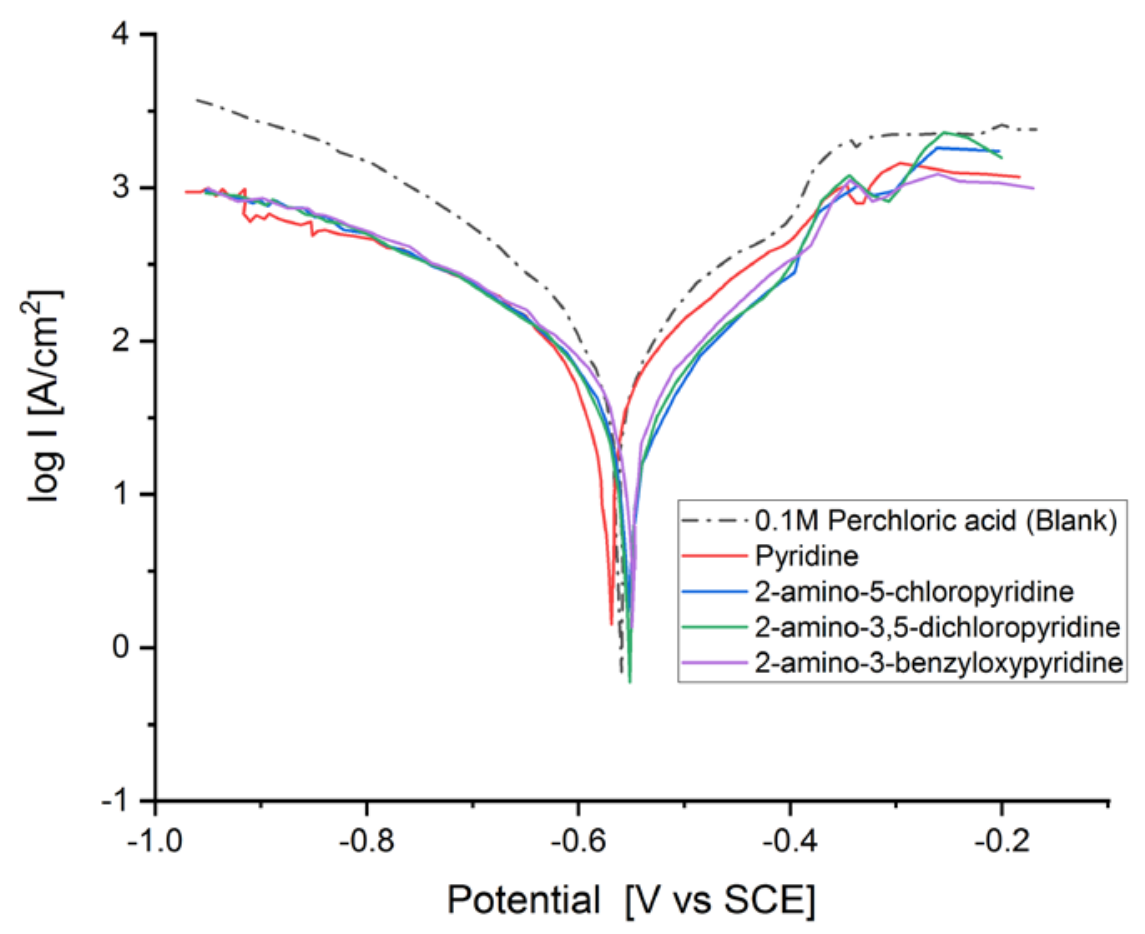

Figure 2. Tafel plot of the mild steel (MS) electrode measured in $\mathrm{HClO}_{4}$ solution ( $\left.\mathrm{V}=20 \mathrm{~cm}^{3}, \mathrm{c}=0.1 \mathrm{M}\right)$ in the absence and the presence of $5 \times 10^{-2} \mathrm{M}$ of the corresponding pyridine inhibitors.

Table 1. The inhibition efficiency (IE (\%)) and the chemical structure of the pyridine inhibitors.

Corrosion Media

\subsection{DFT}

The geometry of the HOMO and LUMO orbitals are recognized as key factors for assessing the reactivity of a molecule and the progression of chemical reactions [19]. The possible electron-donating 
areas of the molecule are portrayed by HOMO distribution, whereas LUMO indicates the areas with a high tendency to accept electrons from nucleophilic species.

The Highest Occupied Molecular Orbital (HOMO) and Lowest Unoccupied Molecular Orbital (LUMO) and Molecular Electrostatic Potential (MEP) of the studied corrosion inhibitors are presented in Figure 3, and numerous DFT indices are given in Table 2. The MO's picture revealed that in the studied inhibitors, $\mathrm{HOMO}$ was primarily distributed over their pyridine ring with partial distribution on the substituent side.
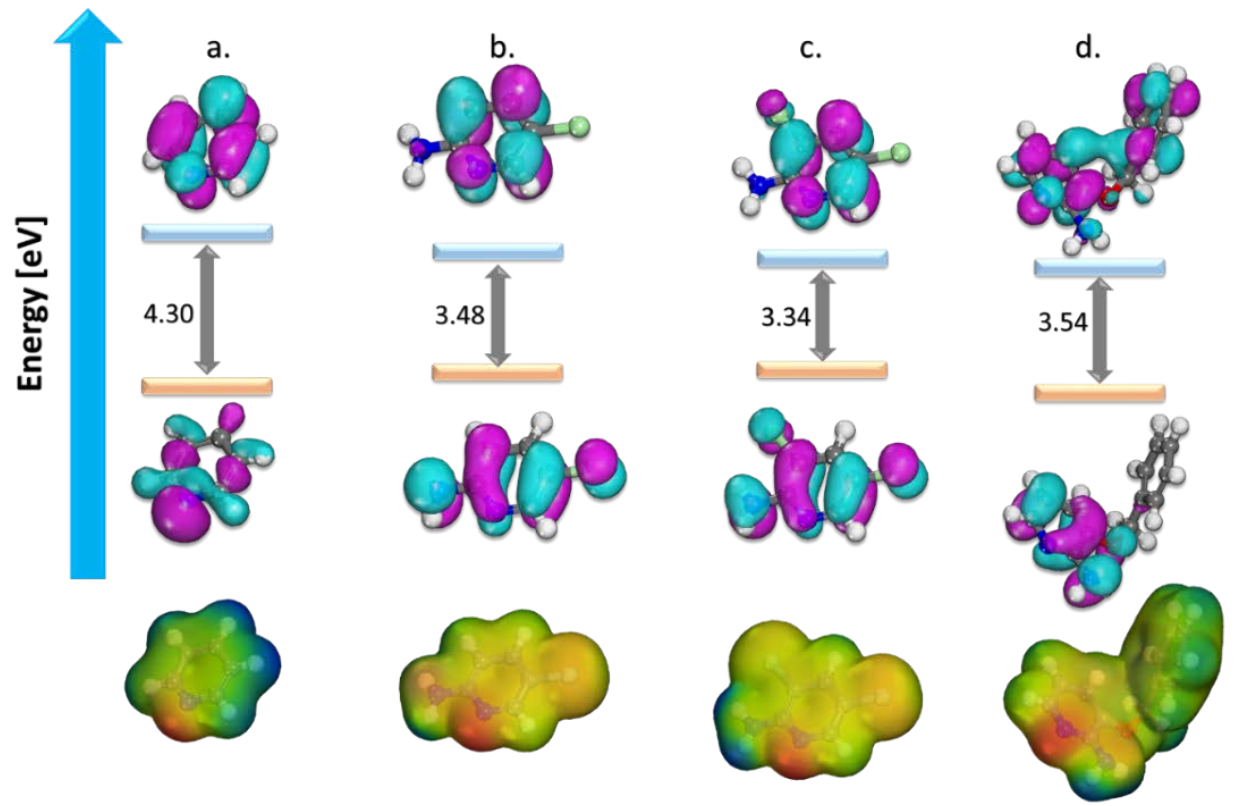

Figure 3. Optimized structure, HOMO, LUMO surfaces, and MEP for (a) pyridine, (b) 2-amino-5-chloropyridine, (c) 2-amino-3,5-dichloropyridine, and (d) 2-amino-3-benzyloxypyridine.

Table 2. The inhibition efficiency and the chemical structure of the pyridine inhibitors.

\begin{tabular}{ccccc}
\hline Descriptors & Pyridine & $\begin{array}{c}\text { 2-Amino-3- } \\
\text { benzyloxypyridine }\end{array}$ & $\begin{array}{c}\text { 2-Amino-3,5- } \\
\text { dichloropyridine }\end{array}$ & $\begin{array}{c}\text { 2-Amino-5- } \\
\text { chloropyridine }\end{array}$ \\
\hline HOMO & -6.5889 & -4.9650 & -5.4760 & -5.4980 \\
LUMO & -0.5481 & -1.4210 & -2.1320 & -2.0130 \\
$\Delta$ E(HOMO-LUMO) & 6.0408 & 3.5440 & 3.3440 & 3.4850 \\
Ionization energy (I) & 6.5889 & 4.9650 & 5.4760 & 5.4980 \\
Electron affinity $(\mathrm{A})$ & 0.5481 & 1.4210 & 2.1320 & 2.0130 \\
Electronegativity $(\mathrm{X})$ & 3.5685 & 3.1930 & 3.8040 & 3.7555 \\
Global hardness $(\eta)$ & 3.0204 & 1.7720 & 1.6720 & 1.7425 \\
Chemical potential $(\pi)$ & -3.5685 & -3.1930 & -3.8040 & -3.7555 \\
Global softness $(\sigma)$ & 0.3311 & 0.5643 & 0.5981 & 0.5739 \\
Global electrophilicity $(\omega)$ & 2.1080 & 2.8768 & 4.3273 & 4.0470 \\
Electrodonating $(\omega-)$ power & 4.2698 & 4.6948 & 6.4383 & 6.1426 \\
Electroaccepting $(\omega+)$ power & 0.7013 & 1.5018 & 2.6343 & 2.3871 \\
Net electrophilicity $(\Delta \omega+-)$ & 0.4671 & 1.2888 & 2.4790 & 2.2243 \\
Fraction of transferred & -0.0560 & 1.0742 & 0.9557 & 0.9310 \\
electrons $(\Delta \mathrm{N})$ & & & & 1.5103 \\
Energy from Inhibitor to & 0.0095 & 2.0448 & -5273 & -0.4356 \\
Metals $(\Delta \mathrm{N})$ & -0.7551 & -0.4430 & -0.4180 & \\
$\Delta$ E back-donation & & &
\end{tabular}

The LUMO distribution had some differences in pyridine ring and was absent in the substituent part (amino groups, chlorine atoms, or benzyloxy ring). The relatively high values of HOMO for the molecules were a measure of the inhibitors and reflect their aptitude for interacting with the iron surface, by electron-donation and acceptance in like manner. This is promoted by their relatively small 
electron affinity and high ionization potential values, thus endorsing a comparable order of electron exchange capacity.

Likewise, high values of $\sigma$ and relatively low values of $\eta$ were also anticipated values to support that these molecules were very reactive species and have an adsorptive tendency when they neighbor metal surfaces. The fraction of transferred electrons $(\Delta \mathrm{N})$ in the inhibitors (ranging from 0.0095 to 2.0448 depending on their chemical structure) reveals the solid ability of these inhibitors for electron donation to the metal surface $[9,20,23,25]$.

Mulliken atomic charges (MAC) were demonstrated as a valuable parameter for the designation of the accountable sites (atoms) of the inhibitors that were prone to adsorption onto the metals. The interaction between $\mathrm{Fe}(110)$ and the inhibitor molecules was frequently taken to favorably occur on the atom with a large negative charge $[19,21,22,25]$. The MAC value for the inhibitors is presented in Figure 4, where the highest negative charge on all of the inhibitor molecules are located on nitrogen atoms (and also on $\mathrm{O}$ for the 2-amino-3-benzyloxypyridine molecule), denoting that these centers have the largest electron density and interact with the $\mathrm{Fe}(110)$. This electron density is visible also in Figure 3 in the visualized electrostatic potential (MEP) for the pyridine molecules.
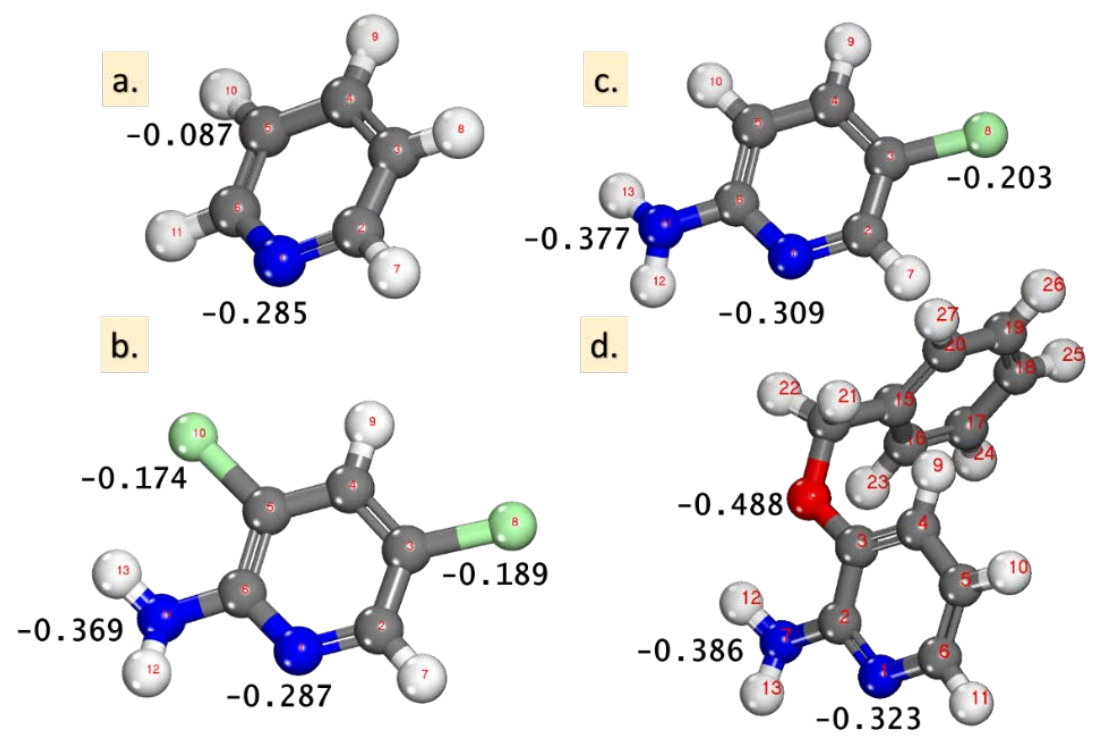

Figure 4. The optimized inhibitor structures: (a) pyridine, (b) 2-amino-5-chloropyridine, (c) 2-amino-3,5dichloropyridine, and (d) 2-amino-3-benzyloxypyridine, with the highest values of the Mulliken atomic charges (MAC).

\subsection{Monte Carlo and Molecular Dynamic Simulations}

The interaction of the inhibitor onto the MS gives the means to evaluate the adsorption energetics of this process. Quantitatively, this is achieved by using the following equation [9,11,24-26]:

$$
E_{\text {adsorption }}=E_{F e(110) / \text { inhibitor }}-\left(F e_{(110)}+E_{\text {inhibitor }}\right) \text {, }
$$

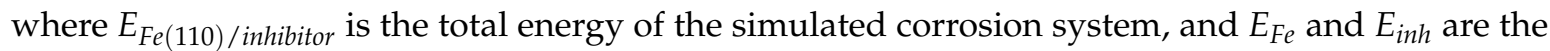
total calculated energy of the $\mathrm{Fe}(110)$ surface and that of the free inhibitor molecule, respectively.

Figure 5 presented the lowest energy configurations of pyridine compounds on the MS in the simulated corrosion media. The pyridine inhibitors were absorbed in the flat-lying manner on the $\mathrm{Fe}(110)$ surface. 
a.

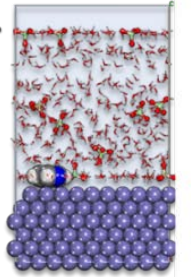

b.

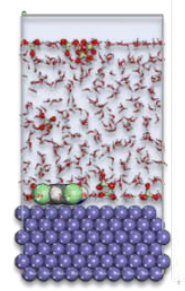

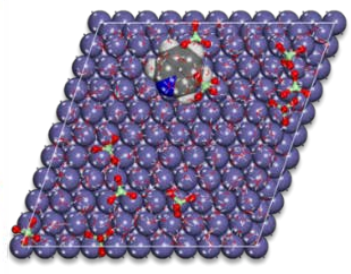

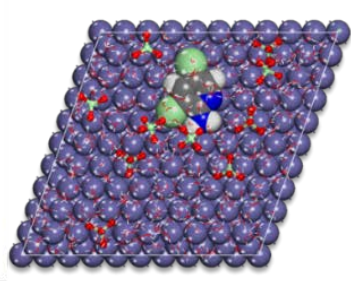

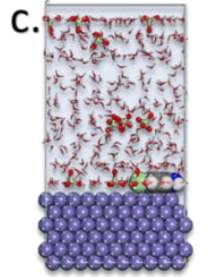

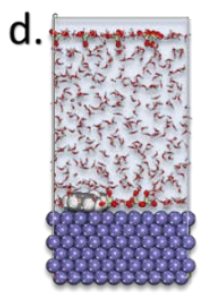

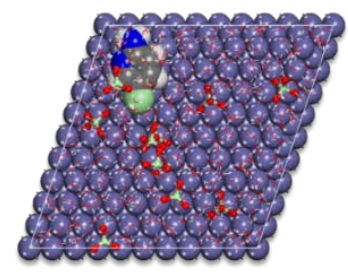

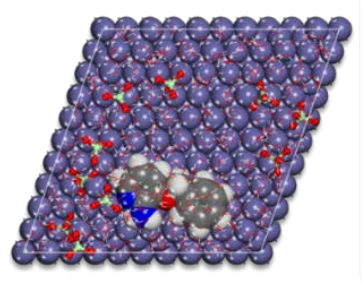

Figure 5. MD poses of the lowest adsorption configurations for the pyridine inhibitors: (a) pyridine, (b) 2-amino-5-chloropyridine, (c) 2-amino-3,5-dichloropyridine, and (d) 2-amino-3-benzyloxypyridine in the simulated corrosion media on the $\mathrm{Fe}(110)$ substrate.

As directed by Mulliken charges, the flat-lying adsorption geometries suggest that this process was supported mostly through nitrogen atoms. This adsorption behavior led to the creation of the protective corrosion layer on the $\mathrm{Fe}(110)[8-11,20,21,23,26]$.

The distribution of the adsorption energies for the large number of adsorptive configurations produced and calculated by the Monte Carlo method for the pyridine inhibitors is shown in Figure 6. The Adsorption Energy (Eads) onto Fe(110) surface values for the adsorption of the inhibitors are as follows: Eads for Pyridine is in a range from -18.35 to $-57.30 \mathrm{kcal} / \mathrm{mol}$ (maximum value of Eads is $-55.25 \mathrm{kcal} / \mathrm{mol}$ ); for the 2-amino-5-chloropyridine, Eads is in a range from -52.55 to $-83.45 \mathrm{kcal} / \mathrm{mol}$ (maximum value of Eads is $-78.75 \mathrm{kcal} / \mathrm{mol}$ ); for the 2-amino-3,5-dichloropyridine, the Eads is in a range from -57.45 to $-95.05 \mathrm{kcal} / \mathrm{mol}$ (maximum value of Eads is $-89.45 \mathrm{kcal} / \mathrm{mol}$ ); and for the 2-amino-3-benzyloxypyridine, Eads is in a range from -65.25 to $-137.85 \mathrm{kcal} / \mathrm{mol}$ (maximum value of Eads is $-93.05 \mathrm{kcal} / \mathrm{mol}$ ). These relatively high adsorption energies point toward a strong interaction of the inhibitors onto the MS surface, leading to efficient corrosion protection of iron.

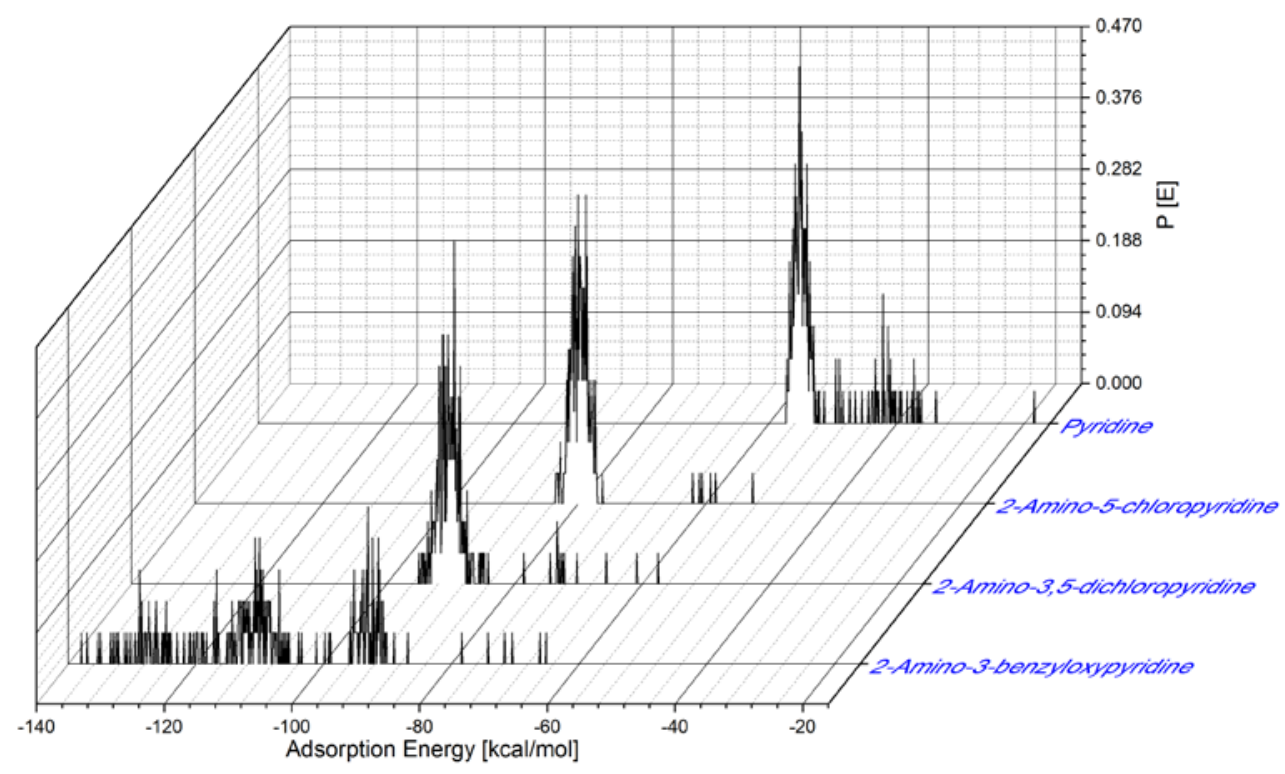

Figure 6. Distribution of adsorption energies for pyridine inhibitors onto the Fe(110) surface. 
From Figure 5, it is evident that the pyridine compounds adsorb effectively on the MS surface. The molecules are oriented toward the iron surface in the position that allows them maximum contact with nitrogen atoms (as suggested by Mulliken charges). This conclusion is supported also by the analysis of the Radial Distribution Function (RDF) calculated for the atoms of the Fe(110) surface presented in Figure 7. The RDF has proven to be a useful means for the evaluation of the interaction of inhibitors with the surface [15].

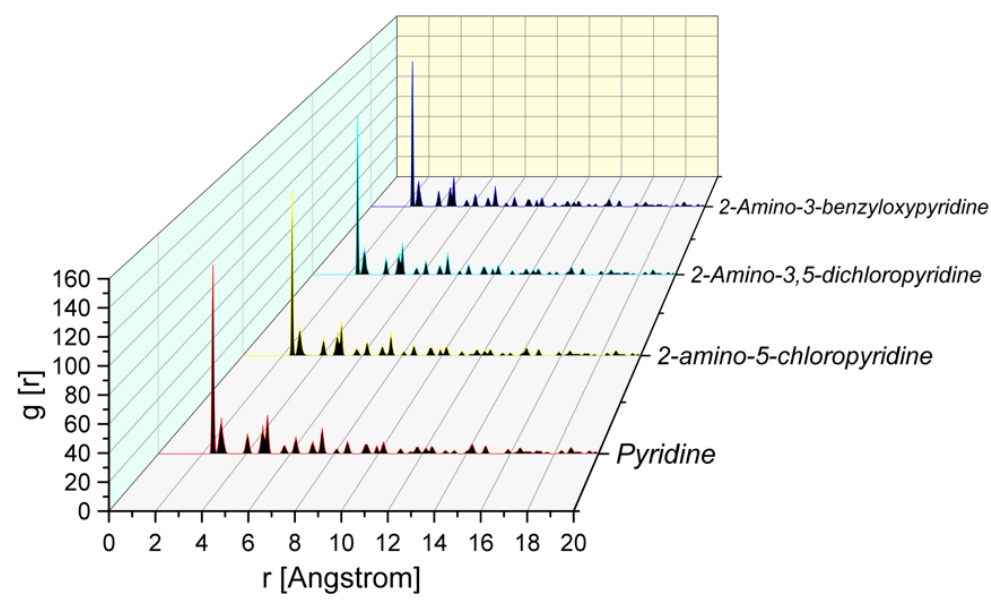

Figure 7. Radial Distribution Function (RDF) of pyridine ring $\mathrm{N}$ atom for different pyridine compounds on the $\mathrm{Fe}(110)$ surface obtained from MD trajectory analysis.

In general, when in the RDF graph, the peak appears in the distance from 1 to $3.5 \AA$ from the metal surface, it corresponds to chemisorption; while in the case of physisorption, the appearance of the RDF peaks is at greater distance values than $3.5 \AA$ [9-11,20,21]. The RDF of $N$ for all of the studied inhibitors had a smaller value than $3.5 \AA$. The results obtained from MD and corresponding RDF analysis confirmed once again (coherent with experimental results and MC calculations) the strong tendency of the inhibitors to adsorb and protect the metal, due to its greater tendency to provide electrons to and receive electrons from the metal surface $[7,9,21,24,26]$.

\subsection{Adsorption and Corrosion Inhibition Mechanism of the Pyridine Compounds}

The corrosion inhibition expressed by an inhibitor was determined principally on their adsorptive affinity on the metal/solution interface that leads to the formation of a protective film onto the metal, preventing its surface exposure toward the corrosion media [40,41].

From the obtained experimental and theoretical results, we propose the adsorption mechanism presented in Figure 8. The pyridine inhibitors were chemically adsorbed onto the MS surface by donor/acceptor interaction amongst free electron pairs of heteroatoms $(\mathrm{N}, \mathrm{O}$, and $\mathrm{Cl})$ and the vacant d-orbital of the MS surface. An important factor on the adsorption was the donor/acceptor interaction among the anti-bonding molecular orbitals of pyridine inhibitors and the d-orbitals of iron atoms of the surface [40]. 


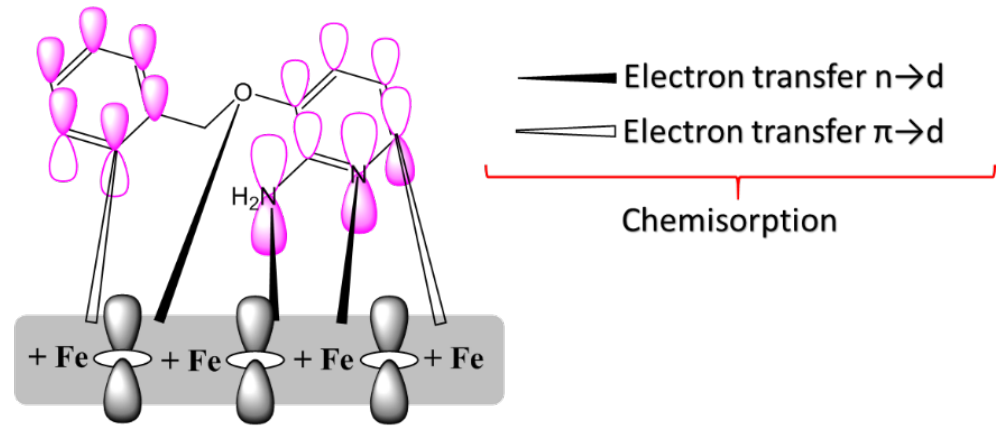

Figure 8. Representation of adsorption of one of the pyridine derivatives on MS surface.

\subsection{The Study of the Film Density and the Self-Diffusion Coefficients of Inhibitors}

After the 1000 ps of MD (Step III of Figure 1), the density values of the pyridine formed films were obtained, and the average density values are presented in Table 3.

Table 3. Parameters for corrosion thin-film model construction.

\begin{tabular}{cccccc}
\hline Inhibitor & $\begin{array}{c}\mathbf{a}=\mathbf{b}=\mathbf{c} \\
{[\AA \mathbf{\AA}]}\end{array}$ & $\begin{array}{c}\alpha=\beta=\gamma \\
{\left[{ }^{\circ}\right]}\end{array}$ & $\begin{array}{c}\text { Density } \\
{\left[\mathrm{g} / \mathbf{c m}^{3}\right]}\end{array}$ & $\begin{array}{c}\text { Number of } \\
\text { Molecules }\end{array}$ & $\begin{array}{c}\text { Number of } \\
\text { Particles }\end{array}$ \\
\hline $\begin{array}{c}\text { Pyridine (A) } \\
18.56\end{array}$ & 90 & 1.052 & 50 & 1 \\
2-amino-5-chloropyridine (B) & 20.33 & 90 & 1.290 & 50 & 1 \\
2-Amino-3,5-dichloropyridine (C) & 21.09 & 90 & 1.460 & 50 & 1 \\
2-Amino-3-benzyloxypyridine (D) & 24.61 & 90 & 1.126 & 50 & 1 \\
\hline
\end{tabular}

The fractional free volume (FFV) of the inhibitor films were evaluated from the (step IV) free and the occupied volumes of the Connolly surface using the following equation [12,42]:

$$
F F V=\frac{V_{\text {free }}}{V_{\text {free }}+V_{\text {occupied }}},
$$

where $V_{\text {free }}$ is the free volume and $V_{\text {occupied }}$ is the occupied volume of the PBC box containing the inhibitor film.

The determination of the self-diffusion coefficient (SDC) is calculated by [12]:

$$
D=\frac{1}{6} \lim _{t \rightarrow \infty} \frac{d}{d t} \sum_{i=1}^{N \alpha}\left\langle\left(r_{i}(t)-r_{i}(0)\right)^{2}\right\rangle,
$$

where the $\left\langle\left(r_{i}(t)-r_{i}(0)\right)^{2}\right\rangle$ is the mean squared displacement values obtained from MD trajectory.

The FFV of the corrosive perchlorate ions was calculated and is shown with other parameters in Table 4.

Table 4. The calculated values of FFV and self-diffusion coefficient of inhibitor molecules in the formed inhibitor films in the presence of perchlorate ion.

\begin{tabular}{ccccc}
\hline Molecule & Pyridine (A) & $\begin{array}{c}\text { 2-Amino-5- } \\
\text { chloropyridine (B) }\end{array}$ & $\begin{array}{c}\text { 2-Amino-3,5- } \\
\text { dichloropyridine (C) }\end{array}$ & $\begin{array}{c}\text { 2-Amino-3- } \\
\text { benzyloxypyridine (D) }\end{array}$ \\
\hline $\begin{array}{c}\text { (Self-diffusion } \\
\text { coefficient) } \times 10^{-5}\left[\mathrm{~cm}^{2} / \mathrm{s}\right]\end{array}$ & 1.923 & 3.073 & 2.651 & 2.186 \\
Free volume $\left[\AA^{3}\right]$ & 1348.6 & 4198.18 & 6227.38 & 4758.87 \\
Occupied volume $\left[\AA^{3}\right]$ & 5521.55 & 6862.28 & 7751.31 & $12,374.34$ \\
FFV & 0.196 & 0.380 & 0.445 & 0.278 \\
\hline
\end{tabular}

At the interface of the formed inhibitor film, a parameter that influences the mobility of corrosive ions (hydronium and perchlorate ions) is the mobility of the inhibitors. The film-forming inhibitor 
molecules interact and are displaced in the corrosive solution through the van der Waals force and Coulomb force, thereby changing the volume and the shape of the cavities in the film $[12,43]$. This influences the mobility of corrosive ions into the film. A high mobility film indicates a larger diffusion coefficient for the corrosive species. The SDC was proposed to measure the mobility of the inhibitor film. From Table 4, the values of the self-diffusion coefficients for the inhibitors are in the range of 1.92 to $3.73 \times 10^{-5} \mathrm{~cm}^{2} / \mathrm{s}$. These values depend on the equilibrium between the molecule flexibility and their ability to interact with surrounding neighboring molecules. The more pronounced effects, in this case, are observed following the order: $\mathrm{B}>\mathrm{C}>\mathrm{D}>\mathrm{A}$. This observation suggests better packing of the pyridine molecules. In the case of other derivatives, although the addition of substituents seems to affect their close packing, this increases the interactions among them. Therefore, in comparison to pyridine, they possess lower values of the self-diffusion coefficient. The reflection of the inhibition performance of an inhibitor molecule is a complex process and is accumulative of many combined effects (volume of the molecule, adsorption ability, adsorption energy, the FFV of the film, the mobility of the film-forming molecules, the interaction of the corrosive species with the film, etc.).

Higher FFV implies that the inhibitor film could afford more or superior voids for the corrosive ion to move through the inhibitor film. Therefore, the high FFV meant a large diffusion coefficient. The largest FFV values indicate a larger space (voids) for the transfer of corrosive species toward the corrosion film. The FFV values follow the order: $\mathrm{C}>\mathrm{B}>\mathrm{D}>\mathrm{A}$. These values correlate to the increase in the SDC of the corresponding film-forming pyridines.

\section{Conclusions}

The inhibition efficiency of several pyridine derivatives was explored experimentally and theoretically (using DFT, MC, and MD). Electrochemical measurements evidenced a relatively robust inhibition performance of these molecules toward MS corrosion in perchlorate acid. These experimental results were rationalized by theoretical methods. DFT calculations were able to put in evidence the responsible adsorption centers of the inhibitors. Moreover, the MC and MD calculations revealed the strong adsorption interaction of pyridine inhibitors towards the iron surface, offering molecular details vis-à-vis the adsorption behavior (geometry) and the adsorption energy of these molecules on the iron surface. The presented theoretical results (DFT, MC, and MD) are in agreement with the experimental ones.

Funding: This research received no external funding.

Acknowledgments: A.B. acknowledges the support from the Ministry of Education, Science and Technology of Kosovo (Nr.2-5069).

Conflicts of Interest: The author declares no conflict of interest.

\section{References}

1. Van Ooij, W.J.; Zhu, D.; Stacy, M.; Seth, A.; Mugada, T.; Gandhi, J.; Puomi, P. Corrosion protection properties of organofunctional silanes-An overview. Tsinghua Sci. Technol. 2005, 10, 639-664. [CrossRef]

2. Balan, P.; Shelton, M.J.; Ching, D.O.L.; Han, G.C.; Palniandy, L.K. Modified Silane Films for Corrosion Protection of Mild Steel. Procedia Mater. Sci. 2014, 6, 244-248. [CrossRef]

3. Kosian, M.; Smulders, M.M.J.; Zuilhof, H. Structure and Long-Term Stability of Alkylphosphonic Acid Monolayers on SS316L Stainless Steel. Langmuir 2016, 32, 1047-1057. [CrossRef] [PubMed]

4. Podvorica, F.I.; Combellas, C.; Delamar, M.; Kanoufi, F.; Pinson, J. Passivation of Metals and Semiconductors, and Properties of Thin Oxide Layers; Elsevier: Amsterdam, The Netherlands, 2006.

5. Berisha, A.; Combellas, C.; Kanoufi, F.; Pinson, J.; Podvorica, F. Physisorption vs grafting of aryldiazonium salts onto iron: A corrosion study. Electrochimica Acta 2011, 56, 10762-10766. [CrossRef]

6. Mehmeti, V.V.; Berisha, A.R. Corrosion study of mild steel in aqueous sulfuric acid solution using 4-methyl-4h-1,2,4-triazole-3-thiol and 2-mercaptonicotinic acid-an experimental and theoretical study. Front. Chem. 2017, 61. [CrossRef] 
7. Guo, L.; Qi, C.; Zheng, X.; Zhang, R.; Shen, X.; Kaya, S. Toward understanding the adsorption mechanism of large size organic corrosion inhibitors on an Fe (110) surface using the DFTB method. RSC Adv. 2017, 7, 29042-29050. [CrossRef]

8. Dagdag, O.; Berisha, A.; Safi, Z.; Hamed, O.; Jodeh, S.; Verma, C.; Ebenso, E.E.; El Harfi, A. DGEBA-polyaminoamide as effective anti-corrosive material for $15 \mathrm{CDV} 6$ steel in $\mathrm{NaCl}$ medium: Computational and experimental studies. J. Appl. Polym. Sci. 2019, 137, 137. [CrossRef]

9. Dagdag, O.; Hsissou, R.; Berisha, A.; Erramli, H.; Hamed, O.; Jodeh, S.; El Harfi, A. Polymeric-Based Epoxy Cured with a Polyaminoamide as an Anticorrosive Coating for Aluminum 2024-T3 Surface: Experimental Studies Supported by Computational Modeling. J. Bio- Tribo-Corrosion 2019, 5. [CrossRef]

10. Hsissou, R.; Benhiba, F.; Abbout, S.; Dagdag, O.; Benkhaya, S.; Berisha, A.; Erramli, H.; Elharfi, A. Trifunctional epoxy polymer as corrosion inhibition material for carbon steel in $1.0 \mathrm{M} \mathrm{HCl}$ : MD simulations, DFT and complexation computations. Inorg. Chem. Commun. 2020, 115, 107858. [CrossRef]

11. Hsissou, R.; Benzidia, B.; Rehioui, M.; Berradi, M.; Berisha, A.; Assouag, M.; Hajjaji, N.; Elharfi, A. Anticorrosive property of hexafunctional epoxy polymer HGTMDAE for E24 carbon steel corrosion in $1.0 \mathrm{M}$ $\mathrm{HCl}$ : Gravimetric, electrochemical, surface morphology and molecular dynamic simulations. Polym. Bull 2019, 1-25. [CrossRef]

12. Yu, L.J.; Zhang, J.; Qiao, G.; Yan, Y.G.; Ti, Y.; Zhang, Y. Effect of alkyl chain length on inhibition performance of imidazoline derivatives investigated by molecular dynamics simulation. Mater. Corros. 2011, 64, 225-230. [CrossRef]

13. Asegbeloyin, J.; Ejikeme, P.; Olasunkanmi, L.; Adekunle, A.; Ebenso, E. A Novel Schiff Base of 3-acetyl-4-hydroxy-6-methyl-(2H)pyran-2-one and 2,2'-(ethylenedioxy)diethylamine as Potential Corrosion Inhibitor for Mild Steel in Acidic Medium. Materials (Basel) 2015, 8, 2918-2934. [CrossRef]

14. Al-Amiery, A.A.; Kadhum, A.A.H.; Al Obaidy, A.H.; Mohamad, A.B.; Hoon, P.S. Novel Corrosion Inhibitor for Mild Steel in $\mathrm{HCl}$. Materials 2014, 7, 662-672. [CrossRef] [PubMed]

15. Al-Amiery, A.A.; Kadhum, A.A.H.; Kadihum, A.; Mohamad, A.B.; How, C.K.; Junaedi, S. Inhibition of Mild Steel Corrosion in Sulfuric Acid Solution by New Schiff Base. Materials 2014, 7, 787-804. [CrossRef]

16. Odewunmi, N.A.; Mazumder, M.A.J.; Mazumder, M.A.J.; Aljeaban, N.A.; Alharbi, B.G.; Al-Saadi, A.A.; Obot, I.B. Impact of Degree of Hydrophilicity of Pyridinium Bromide Derivatives on HCl Pickling of X-60 Mild Steel: Experimental and Theoretical Evaluations. Coatings 2020, 10, 185. [CrossRef]

17. Al-Amiery, A.A.; Al-Majedy, Y.K.; Kadhum, A.A.H.; Mohamad, A.B. New Coumarin Derivative as an Eco-Friendly Inhibitor of Corrosion of Mild Steel in Acid Medium. Mol. 2014, 20, 366-383. [CrossRef]

18. López, D.; Schreiner, W.; De Sánchez, S.; Simison, S. The influence of inhibitors molecular structure and steel microstructure on corrosion layers in CO2 corrosion. Appl. Surf. Sci. 2004, 236, 77-97. [CrossRef]

19. Berisha, A.; Podvorica, F.; Mehmeti, V.; Syla, F.; Vataj, D. Theoretical and experimental studies of the corrosion behavior of some thiazole derivatives toward mild steel in sulfuric acid media. Maced. J. Chem. Chem. Eng. 2015, 34, 287. [CrossRef]

20. Hsissou, R.; Abbout, S.; Berisha, A.; Berradi, M.; Assouag, M.; Hajjaji, N.; Elharfi, A. Experimental, DFT and molecular dynamics simulation on the inhibition performance of the DGDCBA epoxy polymer against the corrosion of the E24 carbon steel in $1.0 \mathrm{M} \mathrm{HCl}$ solution. J. Mol. Struct. 2019, 1182, 340-351. [CrossRef]

21. Mishra, A.; Chandrabhan, V.; Srivastava, V.; Lgaz, H.; Berradi, M.; Quraishi, M.A.; Ebenso, E.E.; Chung, I.-M. Chemical, electrochemical and computational studies of newly synthesized novel and environmental friendly heterocyclic compounds as corrosion inhibitors for mild steel in acidic medium. J. Bio- Tribo-Corrosion 2018, 4. [CrossRef]

22. Dagdag, O.; Berisha, A.; Safi, Z.; Dagdag, S.; Berrani, M.; Jodeh, S.; Verma, C.; Ebenso, E.E.; Wazzan, N.; El Harfi, A. Highly durable macromolecular epoxy resin as anticorrosive coating material for carbon steel in $3 \%$ $\mathrm{NaCl}$ : Computational supported experimental studies. J. Appl. Polym. Sci. 2020. [CrossRef]

23. Hsissou, R.; Abbout, S.; Seghiri, R.; Rehioui, M.; Berisha, A.; Erramli, H.; Assouag, M.; Elharfi, A. Evaluation of corrosion inhibition performance of phosphorus polymer for carbon steel in $[1 \mathrm{M}] \mathrm{HCl}$ : Computational studies (DFT, MC and MD simulations). J. Mater. Res. Technol. 2020. [CrossRef]

24. Dagdag, O.; Hsissou, R.; El Harfi, A.; Berisha, A.; Safi, Z.; Verma, C.; Ebenso, E.E.; Touhami, M.E.; El Gouri, M. Fabrication of polymer based epoxy resin as effective anti-corrosive coating for steel: Computational modeling reinforced experimental studies. Surfaces Interfaces 2020, 18, 100454. [CrossRef] 
25. Abbout, S.; Zouarhi, M.; Chebabe, D.; Damej, M.; Berisha, A.; Hajjaji, N. Galactomannan as a new bio-sourced corrosion inhibitor for iron in acidic media. Heliyon 2020, 6, e03574. [CrossRef]

26. Hsissou, R.; Dagdag, O.; Abbout, S.; Benhiba, F.; Berradi, M.; El Bouchti, M.; Berisha, A.; Hajjaji, N.; Elharfi, A. Novel derivative epoxy resin TGETET as a corrosion inhibition of E24 carbon steel in $1.0 \mathrm{M} \mathrm{HCl} \mathrm{solution.}$ Experimental and computational (DFT and MD simulations) methods. J. Mol. Liq. 2019, 284, 182-192. [CrossRef]

27. Zhang, J.; Liu, J.; Yu, W.; Yan, Y.; You, L.; Liu, L. Molecular modeling of the inhibition mechanism of 1-(2-aminoethyl)-2-alkyl-imidazoline. Corros. Sci. 2010, 52, 2059-2065. [CrossRef]

28. Yan, Y.; Wang, X.; Zhang, Y.; Wang, P.; Cao, X.; Zhang, J. Molecular dynamics simulation of corrosive species diffusion in imidazoline inhibitor films with different alkyl chain length. Corros. Sci. 2013, 73, 123-129. [CrossRef]

29. Gupta, R.K.; Malviya, M.; Verma, C.; Gupta, N.K.; Quraishi, M.A. Pyridine-based functionalized graphene oxides as a new class of corrosion inhibitors for mild steel: An experimental and DFT approach. RSC Adv. 2017, 7, 39063-39074. [CrossRef]

30. El-Maksoud, S.A.; Fouda, A.S. Some pyridine derivatives as corrosion inhibitors for carbon steel in acidic medium. Mater. Chem. Phys. 2005, 93, 84-90. [CrossRef]

31. Kosari, A.; Moayed, M.H.; Davoodi, A.; Parvizi, R.; Momeni, M.; Eshghi, H.; Moradi, H. Electrochemical and quantum chemical assessment of two organic compounds from pyridine derivatives as corrosion inhibitors for mild steel in $\mathrm{HCl}$ solution under stagnant condition and hydrodynamic flow. Corros. Sci. 2014, 78, 138-150. [CrossRef]

32. James, A.O.; Oforka, N.C.; Abiola, O.K.; Ita, B.I. A study on the inhibition of mild steel corrosion in hydrochloric acid by pyridoxol hydrochloride. Eclética Química J. 2007, 32, 31-38. [CrossRef]

33. Inada, Y.; Orita, H. Efficiency of numerical basis sets for predicting the binding energies of hydrogen bonded complexes: Evidence of small basis set superposition error compared to Gaussian basis sets. J. Comput. Chem. 2007, 29, 225-232. [CrossRef]

34. Perdew, J.P.; Burke, K.; Ernzerhof, M. Generalized Gradient Approximation Made Simple. Phys. Rev. Lett. 1996, 77, 3865-3868. [CrossRef]

35. Berisha, A.; Combellas, C.; Kanoufi, F.; DeCorse, P.; Oturan, M.A.; Médard, J.; Seydou, M.; Maurel, F.; Pinson, J. Some Theoretical and Experimental Insights on the Mechanistic Routes Leading to the Spontaneous Grafting of Gold Surfaces by Diazonium Salts. Langmuir 2017, 33, 8730-8738. [CrossRef]

36. Tkatchenko, A.; Scheffler, M. Accurate Molecular Van Der Waals Interactions from Ground-State Electron Density and Free-Atom Reference Data. Phys. Rev. Lett. 2009, 102, 073005. [CrossRef]

37. Klamt, A. The COSMO and COSMO-RS solvation models, Wiley Interdiscip. Rev. Comput. Mol. Sci. 2018, 8, e1338.

38. Berisha, A. Interactions between the Aryldiazonium Cations and Graphene Oxide: A DFT Study. J. Chem. 2019, 2019, 1-5. [CrossRef]

39. Sun, H.; Jin, Z.; Yang, C.; Akkermans, R.L.C.; Robertson, S.H.; Spenley, N.A.; Miller, S.; Todd, S.M. COMPASS II: Extended coverage for polymer and drug-like molecule databases. J. Mol. Model. 2016, 22, 1-10. [CrossRef]

40. Lgaz, H.; Bhat, K.S.; Salghi, R.; Jodeh, S.; Shubhalaxmi; Algarra, M.; Hammouti, B.; Ali, I.H.; Essamri, A. Insights into corrosion inhibition behavior of three chalcone derivatives for mild steel in hydrochloric acid solution. J. Mol. Liq. 2017, 238, 71-83. [CrossRef]

41. Yilmaz, N.; Fitoz, A.; Ergun, Ÿ.; Emregül, K. A combined electrochemical and theoretical study into the effect of 2-((thiazole-2-ylimino) methyl)phenol as a corrosion inhibitor for mild steel in a highly acidic environment. Corros. Sci. 2016, 111, 110-120. [CrossRef]

42. Guo, L.; Zhang, S.T.; Li, W.P.; Hu, G.; Li, X. Experimental and computational studies of two antibacterial drugs as corrosion inhibitors for mild steel in acid media. Mater. Corros. 2013, 65, 935-942. [CrossRef]

43. Hofmann, D.; Fritz, L.; Ulbrich, J.; Schepers, C.; Böhning, M. Detailed-atomistic molecular modeling of small molecule diffusion and solution processes in polymeric membrane materials. Macromol. Theory Simul. 2000, 9, 293-327. [CrossRef]

(C) 2020 by the author. Licensee MDPI, Basel, Switzerland. This article is an open access article distributed under the terms and conditions of the Creative Commons Attribution (CC BY) license (http://creativecommons.org/licenses/by/4.0/). 